\title{
Dynamic Comovements Between Housing and Oil Markets in the US over 1859 to 2013: a Note
}

\author{
Nikolaos Antonakakis ${ }^{1,2}$ (D) . Rangan Gupta ${ }^{3}$. \\ John W. Muteba Mwamba 4
}

\begin{abstract}
In this study, we examine the dynamic comovements between housing and oil market returns in the United States over the period 1859-2013, while controlling for real gross domestic product growth, inflation, interest rates, and real stock, gold and silver returns that are known to affect both these markets. As such, we provide a bird's-eye view on the interdependencies between these two markets from a historical perspective. The results of our empirical analysis reveal that comovements between housing and oil market returns are consistently negative over time, apart from several recessions the U.S. economy experienced in the 19th century, wherein correlations were positive.
\end{abstract}

Keywords Housing market · Oil market · Dynamic comovements

JEL Classification $\mathrm{C} 32 \cdot \mathrm{E} 60 \cdot \mathrm{E} 66 \cdot \mathrm{G} 10$

Nikolaos Antonakakis

nikolaos.antonakakis@webster.ac.at

1 Economics and Finance Subject Group, University of Portsmouth, Portsmouth Business School, Portland Street, Portsmouth PO1 3DE, UK

2 Department of Business and Management, Webster Vienna Private University, Praterstrasse 23, 1020 Vienna, Austria

3 Department of Economics, University of Pretoria, Pretoria 0002, South Africa

4 Department of Economics and Econometrics, University of Johannesburg, Auckland Park 2006, South Africa 


\section{Introduction}

On the one hand, Leamer (2007) notes that eight out of ten post-war recessions in the U.S. were preceded by shocks to the housing sector. This number rises to nine, when we include the recent "Great Recession". In this regard, Nyakabawo et al. (2015) stress the importance of housing prices shocks in particular. On the other hand, Hamilton (2008) indicates that nine of ten recessions in the U.S. since World War II have been preceded by an increase in oil prices. Interestingly, Hamilton (2009) even goes as far as arguing that a large proportion of the recent downturn in the U.S. gross domestic product (GDP) during the "Great Recession" can also be attributed to the oil price shock of 2007-2008. In this regard, Kaufmann et al. (2011) identified a significant long-run (cointegrating) relationship between household expenditures on energy and U.S. mortgage delinquency rates, and hence, postulate a direct role for energy prices in the 2008 financial crisis. In addition, Breitenfellner et al. (2015) analysed, using conditional logit models, the role played by energy inflation as a determinant of downward corrections in housing prices, based on a dataset 18 Organisation for Economic Co-operation and Development (OECD) economies spanning four decades. The authors provided strong evidence that increases in energy price inflation raised the probability of such corrective periods taking place.

Given this, an important research question is to analyse the many channels underlying the relationship between housing and oil prices: ${ }^{1}$ (i) Oil price hikes adversely affect economic growth (as discussed above), and thus, dampen the demand for housing, and reduce the price; (ii) However, oil price increases are likely to increase construction and operational building costs, which might result in a decline in the supply of housing, thus pushing price up; (iii) If there is a tightening of monetary policy to curb the pressure induced by oil price increases on headline inflation, this is likely to withdraw liquidity from the housing market and hence, reduce housing prices through a fall in demand; (iv) However, if housing is used as an inflationhedge, the inflationary-effect of oil prices might increase housing demand and hence, raise prices; (v) An increase in oil returns might also be associated with moving funds into the oil market at the expense of investment in housing as an asset, thus reducing price. So in summary, though an increase in oil price could either increase or decrease housing prices, depending on the strengths of the various channels, it is more likely that the negative impact is likely to dominate on average. Such a presumption has to do with the economy-wide negative impact generally associated with oil price hikes. But this remains to be empirically verified.

Against this backdrop, our paper investigates the time-varying interdependence between real housing returns and real oil returns for the U.S. economy over the annual period of 1859-2013, allowing for a set of control variables (economic growth, inflation and the interest rate) that are known to affect both these markets (Breitenfellner et al. 2015). Specifically, we construct time-varying measures of correlations between real housing market returns and real oil price returns based

\footnotetext{
${ }^{1}$ The reader is referred to Breitenfellner et al. (2015) for a detailed discussion in this regard.
} 
on the dynamic conditional correlation generalised autoregressive conditional heteroskedasticity (DCC-GARCH) model of Engle (2002). Taking into account both time variation and conditional heterogeneity in correlations, the proposed measure has several advantages compared to other commonly used indicators. For instance, it is able to distinguish negative correlations due to single episodes, synchronous behavior during stable years and asynchronous behavior in turbulent years. Unlike rolling windows, an alternative way to capture time variability, the proposed measure does not suffer from the so-called "ghost features," as the effects of a shock are not reflected in $n$ consecutive periods, with $\mathrm{n}$ being the window-span. In addition, under the proposed approach there is neither need to set a window span, nor loss of observations, nor is there a requirement for subsample estimation. To the best of our knowledge this is the first paper to analyse the time-varying relationship between real housing returns and real oil returns covering over 150 years of U.S. history, with the start date corresponding to beginning of the modern era of the petroleum industry with the drilling of the first oil well in the U.S. at Titusville, Pennsylvania in $1859 .^{2}$

At this stage, it is important to indicate the reasons behind our preference to use a DCC-GARCH approach rather than a time-varying vector autoregressive (VAR) method. First, as it is well-known, identifying shocks in a VAR would require us to order the variables. However, at an annual frequency, it is difficult to postulate which variable should be ordered first, i.e. is believed to be more exogenous. Of course, one could use various orderings and check for the robustness of the results. But then again, this would not guard against the possibility that the degree of exogeneity over such a long-span of data did not vary over time. An alternative approach would have been to use sign-restricted time-varying VAR, but this would take away from us the very essence of our exercise of deciphering the correlation between these two variables, which as indicated in the paper could be either positive or negative. In other words, one could not have, without doubt, imposed a theory-based sign either. Keeping these issues in mind, we decided to resort to a DCC-GARCH approach, which provides us with a time-varying correlation between these two variables accounting for heteroscedastic disturbances, without having to worry about the ordering of variables or sign-restrictions in a VAR model. Having said this, one limitation of our approach, given the long time-span of data, is our inability to control for other important variables (like macroeconomic and demographic) which are likely to affect both real housing and oil returns. ${ }^{3}$ In such a multivariate setting, a VAR approach is preferable, as it also allows us to analyze the importance of the other variables (shocks)

\footnotetext{
${ }^{2}$ Using a qualitative vector autoregressive (qual-VAR) model as proposed by Dueker (2005) comprising growth, inflation, interest rate and the recovered dynamic correlation from our DCC-GARCH model, we were able to predict all the recessions accurately over our sample period. The result highlighted the importance of real oil and real housing prices as potential leading indicators of the U.S. economy. Note that, the preferences for a qual-VAR instead of a standard probit model used for predicting recessions is to account for the fact that macroeconomic variables and asset prices, respectively, affect recessions and are also affected by them, in turn (Dueker 2005, Tiwari et al. 2016). Complete details of these results are available upon request from the authors.

${ }^{3}$ But, we have now controlled for the missing variables and especially the two channels as indicated by an anonymous referee, by using alternative investment-related variables (asset prices) and construction costs.
} 
in the relationship between housing prices and oil price. Nevertheless, given that our concern is a time-varying analysis of correlation between these two variables, the DCC-GARCH framework can be considered most appropriate in the context of our study. The results of the empirical analysis reveal that comovements between housing and oil market returns are consistently negative over time, apart from periods of U.S. recessions during the 19th century, wherein correlations are positive.

\section{Methodology}

In order to examine the evolution of co-movements between real housing returns and real oil returns, we obtain a time-varying measure of correlation based on the dynamic conditional correlation (DCC) model of Engle (2002).

Let $y_{t}=\left[y_{1 t}, y_{2 t}\right]^{\prime}$ be a $2 \times 1$ vector comprising the real housing returns and real oil returns. The conditional mean equation of the model is then represented by:

$$
A(L) y_{t}=B(L) x_{t}+\varepsilon_{t}, \text { where } \varepsilon_{t} \mid \Omega_{t-1} \sim N\left(0, H_{t}\right), \text { and } t=1, \ldots, T
$$

where $A$ and $B$ are matrices of endogenous and exogenous variables, respectively, $L$ the lag operator and $\varepsilon_{t}$ is the vector of innovations based on the information set, $\Omega$, available at time $t-1$. The $\varepsilon_{t}$ vector has the following conditional variancecovariance matrix:

$$
H_{t}=D_{t} R_{t} D_{t},
$$

where $D_{t}=\operatorname{diag} \sqrt{h_{i t}}$ is a $2 \times 2$ matrix containing the time-varying standard deviations obtained from univariate $\operatorname{GARCH}(\mathrm{p}, \mathrm{q})$ models as:

$$
h_{i t}=\gamma_{i}+\sum_{p=1}^{P_{i}} \alpha_{i p} \varepsilon_{i t-i p}^{2}+\sum_{q=1}^{Q_{i}} \beta_{i q} h_{i q-q}, \quad \forall i=1,2 .
$$

The DCC(M,N) model of Engle (2002) comprises the following structure:

$$
R_{t}=Q_{t}^{*-1} Q_{t} Q_{t}^{*-1},
$$

where:

$$
Q_{t}=\left(1-\sum_{m=1}^{M} a_{m}-\sum_{n=1}^{N} b_{n}\right) \bar{Q}+\sum_{m=1}^{M} a_{m}\left(\varepsilon_{t-m}^{2}\right)+\sum_{n=1}^{N} b_{n} Q_{t-n} .
$$

$\bar{Q}$ is the time-invariant variance-covariance matrix retrieved from estimating Eq. 3, and $Q_{t}^{*}$ is a $2 \times 2$ diagonal matrix comprising the square root of the diagonal elements of $Q_{t}$. Finally, $R_{t}=\rho_{i j_{t}}=\frac{q_{i j, t}}{\sqrt{q_{i i, t} q_{j j, t}}}$ where $i, j=1,2$ is the $2 \times 2$ matrix comprising the conditional correlations and which are our main focus.

\section{Data}

We use annual data, covering the period 1859-2013. Data for real GDP, Winans International nominal housing prices index for new homes, and West Texas Intermediate 
(WTI) oil prices are extracted from the Global Financial Database (GFD) (2015) database. The stock price index data come from GFD (2015), and the gold and silver price index data from Kitco (2015). The Consumer Price Index (CPI) used to deflate the housing, oil, stock, gold and silver prices to obtain the corresponding real values, is obtained from the website of Sahr (2015). The data on the short-term interest rate is obtained from Homer and Sylla (2005) over 1859-1870, and thereafter from the online data segment on the website of Shiller (2015). Barring the interest rate, all variables are converted to their growth rate forms (by taking the first difference of their natural logarithms) to ensure mean-reversion required for our DCC approach. ${ }^{4}$ Given this, we lose one observation, and our effective sample covers the period of 1860-2013.

\section{Empirical Findings}

Table 1 reports the estimation results of the three bivariate DCC models. Panels A and $\mathrm{B}$ present the conditional mean and variance results, respectively, while Panel C contains the LjungBox Q-Statistics on the standardized and squared standardized residuals, respectively, up to 12 lags. The choice of the lag length of the autoregressive (AR) process of the conditional mean is based on the Akaike information criterion (AIC) and Schwarz Bayesian information criterion (BIC) and serves to remove any serial correlation in the standardized residuals. GDP growth, inflation and interest rates are also included in the conditional mean.

According to the results in returns in Table 1, we observe that increased economic growth leads to positive real housing returns and real oil returns, while increases in the inflation rate leads to negative real housing returns and increased real oil returns. Increases in the interest rate reduce real housing returns, but affect real oil returns positively. Barring the last result of the effect of the interest rate on the real oil returns, all results conform with the theory of housing and oil markets as discussed in the extant literature. The fact that a positive interest movement leads to an increase in real oil returns could be due to the fact that while nominal returns on both oil and inflation fell, the latter declined more. This line of reasoning makes sense, given that in the early part of the sample, the oil market was very volatile as it developed, and then from 1919 to 1976 the WTI oil price was administered. Moreover, a rise in real gold returns is associated with increased real housing returns and real oil returns, while a rise in real stock returns and real silver returns is associated with increased real housing returns and real oil returns, respectively. Interestingly, we observe that real oil returns take time to impact the real housing returns, in the sense that the second lag of real oil returns is more important than the first lag, both economically and significantly. This indicates that, on average, oil price movements take time to affect housing prices. The statistical significance of $a$ and $b$ coefficients (see panel B) suggests that dynamic correlations are indeed time-varying, and the model is well specified (as can be seen from panel C).

\footnotetext{
${ }^{4}$ Complete details of the unit root tests are available upon request from the authors.
} 
Table 1 Estimation results of DCC-GARCH model of real housing and oil returns, period: 1859-2013

\begin{tabular}{|c|c|c|}
\hline & rHouse $R_{t}$ & rOilRet ${ }_{t}$ \\
\hline \multicolumn{3}{|c|}{ Panel A: Conditional mean } \\
\hline \multirow[t]{2}{*}{ Cons } & $2.8080^{*}$ & $-9.8178 * * *$ \\
\hline & $(1.5318)$ & $(1.8747)$ \\
\hline \multirow[t]{2}{*}{$r$ House $R_{t-1}$} & $0.0282 * * *$ & $0.0295^{* * *} *$ \\
\hline & $(0.0061)$ & $(0.0072)$ \\
\hline \multirow{2}{*}{ rHouse $R_{t-2}$} & $0.0107 * * *$ & 0.0271 \\
\hline & $(0.0026)$ & $(0.0958)$ \\
\hline \multirow[t]{2}{*}{ rOilRet R $_{t-1}$} & 0.0124 & $0.0997 * *$ \\
\hline & $(0.0216)$ & $(0.0413)$ \\
\hline \multirow[t]{2}{*}{ rOilRet Pi-2 $_{t}$} & $0.0497 *$ & $0.0451 * * *$ \\
\hline & $(0.0274)$ & $(0.0064)$ \\
\hline \multirow[t]{2}{*}{ Growth $_{t}$} & $0.4296^{* *}$ & $0.2783 * * *$ \\
\hline & $(0.1779)$ & $(0.0713)$ \\
\hline \multirow[t]{2}{*}{$\operatorname{Inf} f_{t}$} & $-0.0393 * * *$ & $0.1920 * * *$ \\
\hline & $(0.0022)$ & $(0.0337)$ \\
\hline \multirow[t]{2}{*}{$\operatorname{Int}_{t}$} & $-0.4562 *$ & $0.8809 * * *$ \\
\hline & $(0.2702)$ & $(0.2494)$ \\
\hline \multirow[t]{2}{*}{$r$ Stock $R_{t}$} & $0.2737 * * *$ & 0.0478 \\
\hline & $(0.0446)$ & $(0.071)$ \\
\hline \multirow[t]{2}{*}{$r G o l d R_{t}$} & $0.1540 * *$ & $0.3968 * * *$ \\
\hline & $(0.0752)$ & $(0.1051)$ \\
\hline \multirow[t]{2}{*}{$r$ Silver $R_{t}$} & 0.0184 & $0.1053 *$ \\
\hline & $(0.0343)$ & $(0.0575)$ \\
\hline
\end{tabular}

Panel B: Conditional variance: $H_{t}=\Gamma^{\prime} \Gamma+A^{\prime} \epsilon_{t-1} \epsilon_{t-1}^{\prime} A+B^{\prime} H_{t-1} B$

$\begin{array}{lll}\gamma & 2.0766^{* * *} & 3.5910 * * \\ \alpha_{1} & (0.2338) & (1.2431) \\ & 0.1125 * * * & 0.1408 * * * \\ \beta_{2} & (0.0154) & (0.0245) \\ & 0.8077 * * * & 0.6223 * * * \\ a & (0.2400) & (0.1274) \\ & 0.2369 * * * & \\ b & (0.0591) & \\ & 0.6235 * * * & \\ & (0.0387) & \end{array}$


Table 1 (continued)

r House $R_{t}$

rOilRet

Panel C: Misspecification tests

$Q(12)$

$Q^{2}(12)$

[0.3512]
[0.3353]

$r$ House $R_{t}$, OilRet $_{t}$, Growth $_{t}$, Inf $_{t}$, Int $_{t}, r$ Stock $R_{t}, r$ Gold $R_{t}$ and $r$ Silver $R_{t}$ denote real housing returns, real oil price returns, real GDP growth, inflation, the first difference of the interest rate, real stock returns, real gold returns, and real silver returns, respectively, at time $t . Q(12)$ and $Q^{2}(12)$ are the Ljung-Box $Q$-Statistics on the standardized and squared standardized residuals, respectively, up to 12 lags. Standard errors in parenthesis and $p$-values in square brackets. $* * *, * *$ and $*$ denote statistical significance at the $1 \%, 5 \%$ and the $10 \%$ level, respectively

Authors' calculations based on data from Homer and Sylla (2005), GFD (2015), Kitco (2015), Sahr (2015) and Shiller (2015)

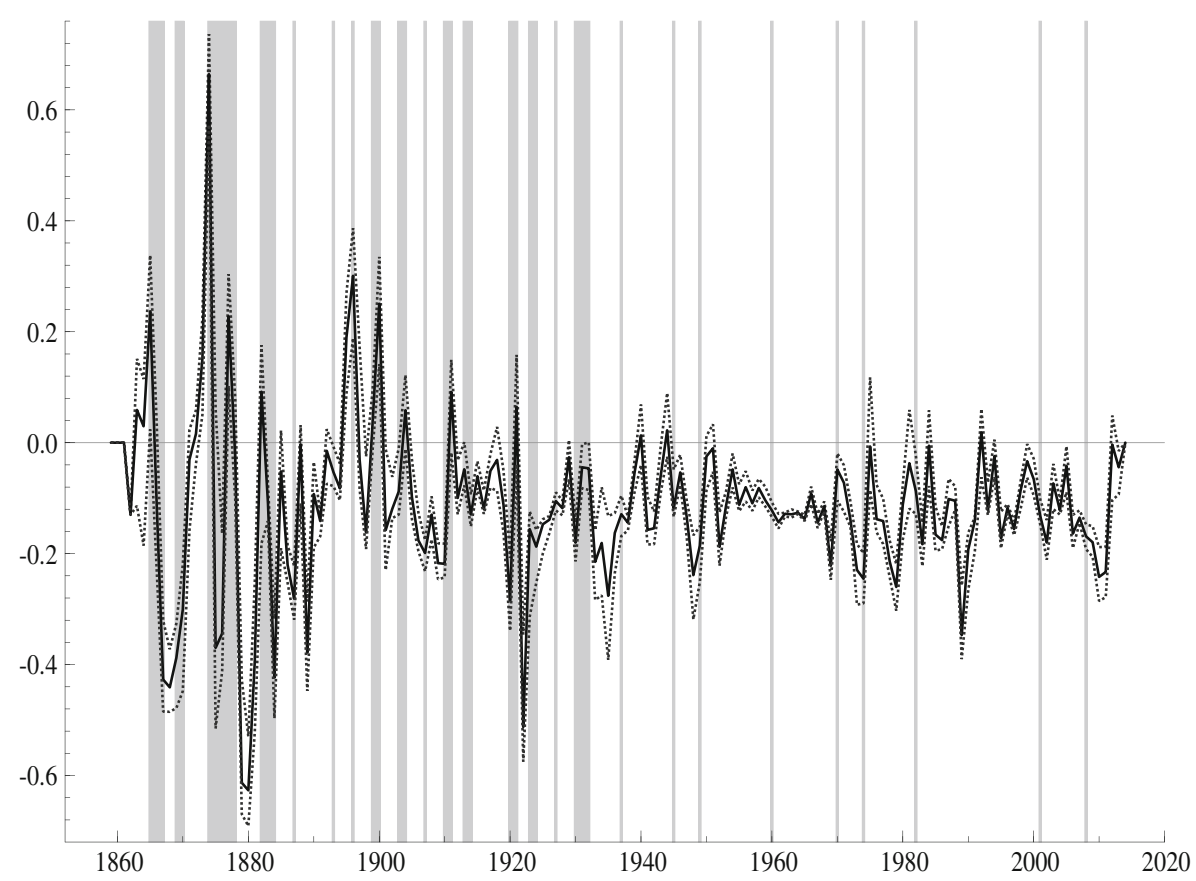

Fig. 1 Dynamic conditional correlations between real house returns and real oil returns. Note: Shading areas denote U.S. recessions as defined by the National Bureau of Economic Research (NBER) business cycles dating committee. Dotted lines denote the $90 \%$ upper and lower confidence intervals. Source: Authors' calculations based on data from Homer and Sylla (2005), GFD (2015), Kitco (2015), Sahr (2015) and Shiller (2015) 
In Fig. 1, we present the corresponding dynamic conditional correlations of the model estimated in Table 1, along with their $90 \%$ confidence intervals. The timevarying correlations between real housing and oil returns are consistently negative over time, apart from several recessions the U.S. economy experienced in the 19th century (i.e. 1865-67, 1874-78, 1896 and 1899-1900), wherein correlations become positive. During the 20th and 21st centuries, however, dynamic correlations between real housing and oil returns are consistently negative. ${ }^{5}$ The fact that there is some evidence of positive correlation between real oil returns and real housing returns in the early part of the sample, especially during the recessionary episodes, indicates that, during these periods of recession, housing was probably acting as an inflation hedge to oil price increases which was the likely source of the recession in the first case. In addition, higher oil prices could have also resulted in higher construction costs and hence, higher housing prices as well. However, as both markets developed obtained financing and became more liquid, the more the standard negative correlation between real oil and housing returns was observed due to growth, monetary policy (liquidity), and investment channels, as discussed in the introduction. ${ }^{6}$

\section{Conclusion}

In this study, we examine the dynamic comovements between housing and oil market returns in the U.S. over the period 1859-2013. Our empirical analysis reveals

\footnotetext{
${ }^{5} \mathrm{We}$ also conducted some additional analysis using two copula functions, namely the normal and the student $-t$ to model the unconditional and conditional dependence structure between real housing and oil price returns. We found a significant negative unconditional dependence structure between the real housing and real oil returns. To understand the evolution of this type of dependence structure, we developed a time varying student- $t$ copula model. This model confirms that the level of the current dependence structure between real oil and real housing returns is a function of the previous dependence between the two. Based on the fitted dependence values, we identified two types of dependence structure, a weak one characterised by positive values (during the late 1800s also observed with our DCC results), and a strong one characterised by negative values. Our sample period was found to be dominated by the strong negative dependence structure. This being a bivariate approach, and since oil and housing returns are likely to be affected by other variables such as interest rate, inflation and real GDP growth as well, we decided not to formally report the copula-based results in the paper. However, complete details of these results are available upon request from the authors.

${ }^{6}$ We conducted additional robustness checks on the DCC-GARCH model based on the suggestions of an anonymous referee. First, we recovered data on construction cost, available from 1890 onwards from the data segment of Professor Robert J. Shiller's webpage (Shiller 2015). We then performed a linear estimation of oil price's effect on the construction cost. We recovered the fit and then used it in the DCC-GARCH model instead of oil price, so as to check whether we still had the negative influence between real housing and real oil returns. The results of the DCC-GARCH model, supported our main findings of a negative influence, especially from 1905 onwards (i.e. similar to our main findings reported in the paper). Second, using the DCC-GARCH model, we also performed causality analysis between real housing and real oil returns and found evidence of bi-directional causality. The causality test based on a constant parameter VAR model, however, only revealed a weak causality from real oil returns to real housing returns. This result highlighted the superiority of a time-varying approach relative to a constant parameter model. Third, realizing the possibility of endogeneity, we replaced the contemporaneous controls of growth, inflation, interest rates, and real returns on stock prices, gold, and silver with their lagged values. However, our results continued to be qualitatively similar. Complete details of these robustness checks are available upon request from the authors.
} 
that comovements between housing and oil market returns are consistently negative over time, apart from periods of U.S. recessions during the 19th century, wherein correlations are positive. Moreover, we find that increased economic growth leads to positive real housing returns and real oil returns, while increases in inflation and interest rates lead to negative real housing returns and increased real oil returns, respectively. In addition, increased real gold returns lead to increased real housing returns and real oil returns, while a rise in real stock returns and real silver returns is associated with increased real housing returns and real oil returns, respectively. Using historical data comes at costs such as the quality of data, as well as its availability. However, we have guarded against these two issues by using data from reliable historical data sources, namely the Global Financial database and www.kitco.com. In addition, to avoid any bias due to missing variables, we have attempted to control for as many related variables as possible (contingent on data availability), that allows us to capture the theoretical channels relating real oil and housing returns. But, indeed, some influences from other important macroeconomic variables, like unemployment, and demographic variables, like fertility, are likely to be missing from our analysis. As part of future research, it would be interesting to extend our analysis by using a sign-restricted time-varying VAR model, which will allow us to identify the oil shocks properly, given that Kilian (2009) indicates that not all oil shocks are alike. We can also study the dynamic impact of oil shocks on housing prices over time using impulse responses functions. ${ }^{7}$ This would, however, mean that we will need to use a shorter sample period, since the variables used to identify various oil shocks (supply, demand and precautionary), are only available post-World War II.

Acknowledgments We thank the Editor and an anonymous reviewer for very helpful suggestions and comments on a previous version of this paper. The usual disclaimer applies.

Open Access This article is distributed under the terms of the Creative Commons Attribution 4.0 International License (http://creativecommons.org/licenses/by/4.0/), which permits unrestricted use, distribution, and reproduction in any medium, provided you give appropriate credit to the original author(s) and the source, provide a link to the Creative Commons license, and indicate if changes were made.

\section{References}

Breitenfellner, A., Cuaresma, J.C., \& Mayer, P. (2015). Energy inflation and house price corrections. Energy Economics, 48, 109-116.

Dueker, M. (2005). Dynamic forecasts of qualitative variables: a qual VAR model of U.S. recessions. Journal of Business \& Economic Statistics, 23, 96-104.

\footnotetext{
${ }^{7}$ Using a constant parameter sign-restricted (for a year) Bayesian VAR, where we imposed that a positive oil shock leads to a fall in output and a rise in price level with interest rate unrestricted, indicated a fall in real housing prices. Similar results were also obtained based on a classical VAR, where the oil shock was identified based on a Choleski (recursive) decomposition with the variables ordered as real oil price, output, price level, real housing prices and interest rate. Complete details of these results are available upon request from the authors.
} 
Engle, R. (2002). Dynamic conditional correlation. Journal of Business \& Economic Statistics, 20(3), $339-350$.

GFD (2015). Global Financial Data. https://www.globalfinancialdata.com/index.html, accessed: 2015-0421.

Hamilton, J.D. (2008). Oil and the macroeconomy in new palgrave dictionary of economics, 2nd edn.: Palgrave McMillan Ltd. Edited by Steven Durlauf and Lawrence Blume.

Hamilton, J.D. (2009). Causes and consequences of the oil shock of 2007-08. Brookings Papers on Economic Activity, 40(1 (Spring)), 215-283.

Homer, S., \& Sylla, R. (2005). A history of interest rates, 4th edn. Wiley Finance, accessed: 2015-04-21.

Kaufmann, R.K., Gonzalez, N., Nickerson, T.A., \& Nesbit, T.S. (2011). Do household energy expenditures affect mortgage delinquency rates? Energy Economics, 33(2), 188-194.

Kilian, L. (2009). Not all oil price shocks are alike: disentangling demand and supply shocks in the crude oil market. The American Economic Review, 99(3), 1053-1069.

Kitco (2015). Kitco Database. http://www.kitco.com, accessed: 2015-04-21.

Leamer, E.E. (2007). Housing is the business cycle. Proceedings -Economic Policy Symposium- Jackson Hole, Federal Reserve Bank of Kansas City, 149-233.

Nyakabawo, W., Miller, S.M., Balcilar, M., Das, S., \& Gupta, R. (2015). Temporal causality between house prices and output in the US: a bootstrap rolling-window approach. The North American Journal of Economics and Finance, 33(C), 55-73.

Sahr, R. (2015). Consumer price index (CPI) conversion factors. http://liberalarts.oregonstate.edu/spp/ polisci/robert-sahr, accessed: 2015-04-21.

Shiller, R.J. (2015). Online Data. http://www.econ.yale.edu/shiller/data.htm, accessed: 2015-04-21.

Tiwari, A.K., Albulescu, C.T., \& Gupta, R. (2016). Time-frequency relationship between US output with commodity and asset prices. Applied Economics, 48(3), 227-242. 